\title{
Chemical Characterization and Kinetic parameter determination under Rancimat test conditions of four monovarietal virgin olive oils grown in Morocco
}

\author{
Said Gharby ${ }^{1, \star}$, Hicham Harhar ${ }^{1}$, Rachid Mamouni ${ }^{2}$, Bertrand Matthäus ${ }^{3}$, El Habib Ait Addi ${ }^{4}$ \\ and Zoubida Charrouf ${ }^{1}$ \\ ${ }^{1}$ Laboratoire de Chimie des Plantes et de Synthèse Organique et Bioorganique, Faculté des Sciences, Université Mohammed V-Agdal, \\ BP 1014, Rabat, Morocco \\ 2 Équipe de Matériaux, Catalyse et Valorisation des Ressources Naturelles, Faculté des Sciences, Université Ibn Zohr, BP 8061 , 8000 Agadir, \\ Morocco \\ 3 Max Rubner-Institut, Federal Research Institute for Nutrition and Food, Working Group for Lipid Research, Detmold, Germany \\ ${ }^{4}$ Équipe de recherche de Biotechnologie, Energie et Environnement, École Supérieure de Technologie, Université Ibn Zohr, B.P. 33/S, \\ Agadir, Morocco
}

\section{Received 5 October 2015 - Accepted 9 March 2016}

\begin{abstract}
The aim of the present investigation is to compare the chemical characterization of four monovarietal virgin olive oils obtained from fruits of olive trees grown in Morocco (Picholine, Picual, Arebiquine, Koroneiki) with kinetic parameters of oxidation based on Rancimat measurements and finally to assess the oxidative stabilities. The examined oils from different varieties showed a chemical composition within the regulatory limits. Rancimat measurements of induction times were carried out under isothermal conditions in an air atmosphere at temperatures from 373 to $423 \mathrm{~K}$ with intervals of $10 \mathrm{~K}$. Using the Arrhenius-type correlation between the inverse induction times and the absolute temperature of the measurements, $E_{a}, Z$, and $k$ values for oil oxidation under Rancimat conditions were calculated. The primary kinetic parameters derived from this method were qualitatively consistent and help to evaluate the oxidative stabilities of oils at increased temperatures.
\end{abstract}

\begin{abstract}
Keywords: Chemical composition / kinetics of oxidation / olive oils / oxidative stability / rancimat
Résumé - Caractérisation chimique et la détermination des paramètres cinétiques sous le test Rancimat de quatre huiles d'olive vierges monovariétales cultivées au Maroc. Le but de ce travail est d'abord de comparer les caractéristiques chimiques de quatre huiles d'olive vierges monovariétales obtenues à partir de fruits d'oliviers cultivés au Maroc (Picholine, Picual, Arbequina, Koroneiki) à l'aide des paramètres cinétiques d'oxydation basés sur des mesures Rancimat et ensuite évaluer leur stabilité à l'oxydation. Ainsi les huiles examinées de différentes variétés ont montré une composition chimique dans les limites réglementaires. Les mesures de Rancimat des temps d'induction ont été effectuées dans des conditions isothermiques, dans une atmosphère d'air à des températures de 373 à $423 \mathrm{~K}$. En utilisant la corrélation de type Arrhenius entre les temps d'induction inverse et de la température absolue des mesures, $E_{a}$, $Z$ et les valeurs de $k$ pour l'oxydation de l'huile dans les conditions de Rancimat ont été calculées. Les paramètres cinétiques primaires dérivés de cette méthode étaient qualitativement cohérents et aident à évaluer la stabilité d'oxydation des huiles à des températures élevées.
\end{abstract}

Mots clés : Composition chimique / cinétique d'oxydation / huiles d'olive / stabilité à l'oxydation / rancimat

\section{Introduction}

Olives from the olive tree (Olea europaea L.) are one of the most important fruits throughout the Mediterranean Basin (Mataix et al., 2008) and in Morocco, with agriculture as one important economic pillar, the cultivation of olive trees constitutes one of the principal economical and agricultural sectors. Olive groves in Morocco are characterized by

\footnotetext{
* Correspondence: s.gharby@yahoo.fr
}

the predominance of the Moroccan variety Picholine, which represents more than $96 \%$ of the national heritage (Gharby et al., 2013). The rest consists of several varieties original from Spain, Greece and Italy (Picual, Arebiquine, Koroneiki).

Olive oil is extensively consumed due to its nutritional value and its organoleptic characteristics (Manai et al., 2008). Besides, it is also used in medicine, recommended since ancient times, for the prevention of cardiovascular diseases and for its anti-oxidative capacity (Allalout et al., 2009; Djebali et al., 2012). Some of these effects are associated with the high 
content of phenolic compounds as well as the high amounts of oleic acid, tocopherols and phytosterols (Allalout et al., 2009; Dabbou et al. 2010; Owen et al., 2000). The amount of these compounds in olive oil is influenced to a large extent by the cultivar, soil, climate conditions, irrigation, degree of ripeness, processing methods and lipid oxidation (Allalout et al., 2009; Djebali et al., 2012; Gharby et al., 2011; Morello et al., 2004).

Lipid oxidation has a negative impact on the functionality of raw materials, sensory and nutritional quality of food, and causes economic losses (Matthäus et al., 2010). The most noticeable result of lipid oxidation is the appearance of an unpleasant flavor often referred to rancid, which modifies the sensory characteristics of the food and thus the acceptance of food by the consumer (Matthäus et al., 2010; Velasco and Dobarganes, 2002; Frankel, 2007; Gharby et al., 2012). A number of accelerated methods have been developed to test the resistance of edible oils to oxidation. All these accelerated methods involve the use of elevated temperatures because it is known that the reaction rate is exponentially related to temperature (Reynhout, 1991). Among these methods, nowadays the Rancimat method is very popular and it is frequently used and reviewed due to its ease of use and reproducibility (Anwar et al., 2003; Hasenhuettl and Wan, 1992; Matthäus, 1996; Mendez et al., 1996). Based on induction times from Rancimat measurements it is very easy to rank the oxidative stability of oils, but any kinetic characterization of their oxidation needs at least additional determinations. Rancimat experiments performed at various temperatures for given oil can be used for the kinetic analysis of the oxidation (Farhoosh et al., 2008; Kowalski, 1989). The efficiency of antioxidants can be compared by Rancimat measurements (Ratusz, 2002). There are also some trials to use data from Rancimat measurements to calculate shelf life predictions, but such trials have recently been questioned (Mancebo-Campos et al. 2007; Marques-Ruiz et al., 2008). It was underlined that the mechanisms of lipid oxidation under Rancimat conditions and at ambient temperature are substantially different. Evaluation of oil stability based on induction periods derived from the Rancimat test and from the analysis of oxidation products from the oil phase can lead to inconsistent results.

The purpose of this paper is to compare the chemical characterization of four monovarietal virgin olive oils grown in Morocco, to calculate the kinetic parameters of oxidation based on Rancimat measurements and finally to assess the oxidative stabilities of these oils.

\section{Materials and methods}

\subsection{Quality parameter}

Acidity index, peroxide value (PV), and extinction coefficients $\left(K_{232}\right.$ and $\left.K_{270}\right)$ determination were carried out following the analytical methods described in the Regulations EEC/2568/91 of the European Union Commission (1991). Acidity was expressed as amount of oleic acid. PV was expressed as milliequivalents of active oxygen per kilogram of oil (meq $\mathrm{O}_{2} / \mathrm{kg}$ oil), and extinction coefficient $K_{232}$ and $K_{270}$ were expressed as the specific extinctions of a $1 \%(\mathrm{w} / \mathrm{v})$ solution of oil in 2,2,4-trimethylpentane measured in a $1 \mathrm{~cm}$ cuvette.

For the determination of the fatty acid composition (ISO $5508,1990)$, the methyl esters were analyzed on a CP-Wax $52 \mathrm{CB}$ column $(30 \mathrm{~m} \times 0.25 \mathrm{~mm}$ i.d.) using helium (flow rate $1 \mathrm{ml} / \mathrm{min}$ ) as carrier gas. Initial oven temperature was set at $170{ }^{\circ} \mathrm{C}$; injector temperature $200{ }^{\circ} \mathrm{C}$; detector temperature $230{ }^{\circ} \mathrm{C}$. Injected volume was $1 \mu \mathrm{l}$ for each analysis.

Sterol composition was determined using the International Standard Organisation method (ISO 6799, 1991). Sterol composition was determined after trimethylsilylation of the crude sterol fraction using a Varian 3800 instrument equipped with a VF-1 ms column (30 m and $0.25 \mathrm{~mm}$ i.d.) and using helium (flow rate $1.6 \mathrm{ml} / \mathrm{mn}$ ) as carrier gas. Column temperature was isothermal at $270{ }^{\circ} \mathrm{C}$, injector and detector temperature was $300^{\circ} \mathrm{C}$. Injected quantity was $1 \mu \mathrm{l}$ for each analysis. Data were processed using Varian Star Workstation v 6.30 (Varian Inc., Walnut Creek, CA, USA).

Tocopherol composition was determined using the International Standard Organisation method (ISO 9936, 2006). High performance liquid chromatography (HPLC) was used for the determination of tocopherols, using a solution of $250 \mathrm{mg}$ of oil in $25 \mathrm{ml}$ of n-heptane and a Shimadzu CR8A HPLC instrument (Champ sur Marne, France) equipped with a C18-Varian column $(25 \mathrm{~cm} \times 4 \mathrm{~mm}$; Varian Inc., Middelburg, The Netherlands). Detection was performed using a fluorescence detector (excitation wavelength $290 \mathrm{~nm}$, detection wavelength $330 \mathrm{~nm}$ ). Eluent used was a 99:1 isooctane/isopropanol $(\mathrm{V} / \mathrm{V})$ mixture, flow rate of $1.2 \mathrm{ml} / \mathrm{min}$.

The polyphenol content was determined using the FolinCiocalteu spectrophotometrically according to the Singleton method (Singleton et al., 1999) using caffeic acid as standard.

\subsection{Rancimat test}

Induction time was determined using the International Standard Organisation method (ISO 6886, 2006). The oxidative stability of each sample was determined as the induction period (IP, h) recorded by a 743 Rancimat (Metrohm, Herisau, Switzerland) apparatus using $3 \mathrm{~g}$ of oil sample. Samples placed into Rancimat standard tubes were subjected to the normal operation conditions of the test by heating at $373 \mathrm{~K}, 383 \mathrm{~K}$, $393 \mathrm{~K}, 403 \mathrm{~K}, 413 \mathrm{~K}, 423 \mathrm{~K}$ with an air flow of $20 \mathrm{~L} / \mathrm{h}$.

\subsection{Kinetic data analysis}

Temperature coefficients $\left(T_{\text {Coeff }}, \mathrm{K}^{-1}\right)$ were determined from the slopes of the lines generated by plotting $\ln (k) v s$. the absolute temperature $(T, \mathrm{~K})$ :

$$
\ln (k)=a(T)+b
$$

where $a$ and $b$ are the equation parameters.

Activation energies $\left(E_{a}, \mathrm{~kJ} / \mathrm{mol}\right)$ and pre-exponential or frequency factors $\left(A, \mathrm{~h}^{-1}\right)$ were determined from the slopes and intercepts, respectively, of the lines generated by plotting $\ln (k)$ vs. $1 / T$ using the Arrhenius equation:

$$
\ln (k)=\ln (A)-\left(E_{\mathrm{a}} / R T\right)
$$


where $k$ is the reaction rate constant or reciprocal OSI $\left(\mathrm{h}^{-1}\right)$, and $R$ is the molar gas constant $(8.3143 \mathrm{~J} / \mathrm{mol} \mathrm{K})$. Also, a temperature acceleration factor, based on the increase in oxidation rate per $10^{\circ} \mathrm{C}$ increase in temperature, known as $Q_{10}$ number, was calculated from the slopes of the lines.

Enthalpies $(\Delta H)$ and entropies $(\Delta S)$ of activation were determined by plotting $\ln (k / T)$ vs. $1 / T$ via the equation derived from the activated complex theory:

$$
\ln (k / T)=\ln \left(k_{r m B} / h\right)+(\Delta S / R)-(\Delta H / R T)
$$

Where $\mathrm{k}_{B}$ is the Boltzmann constant $\left(1.3806586 \times 10^{-23} \mathrm{~J} / \mathrm{K}\right)$ and $h$ is the Planck's constant $\left(6.62607556 \times 10^{-34} \mathrm{~J} \mathrm{~s}\right)$. From the slopes and intercepts of the lines, $\Delta H$ and $\Delta S$ were calculated.

\subsection{Statistical analysis}

Values reported in tables and figures are the means \pm SE of two to three replications. The significance level was set at $P=0.05$. Separation of means was performed by Tukey's test at the 0.05 significance level.

\section{Results and discussion}

\subsection{Initial quality of olive oils}

\subsubsection{Quality indices}

Olive oil quality can be classified into different categories by use of chemical, physical and sensory parameters according to the definitions and standards defined by the Commission Regulation (EEC) No. 2568/91 on the characteristics of olive oil and olive-residue oil and on the relevant methods of analysis (Commission Regulation, 1990). The European Commission has defined the quality of olive oil based on certain parameters and indicators, mainly the degree of acidity, peroxide value, values of specific extinction in the UV absorbance at $232 \mathrm{~nm}$ and $270 \mathrm{~nm}\left(E_{232}\right.$ and $\left.E_{270}\right)$. The acidity of oil is evaluated from the amount of free fatty acids, expressed as grams of oleic acid per $100 \mathrm{~g}$ of oil. It is a simple and effective method to assess and classify the grade of olive oil (Commission Regulation, 1990). Generally, if the oil is extracted from fresh and sound fruits by best practices crushing, oil has a very low acidity (Gharby et al., 2013; Gutierrez et al., 2000). However, during storage, the oil may deteriorate and its acidity increases due to the release of fatty acids by hydrolysis of triacylglycerols.

The highest initial acidity was for Arbequina sample, it reached 0.8/100 g. Moroccan picholine olive oil presented the second highest initial acidity $(0.6 / 100 \mathrm{~g})$. Koroneiki and picual olive oils presented a low initial acidity (0.4/100 and 0.2/100 g, respectively). However, the high level of free fatty acids in Arbequina olive oil $(0.8 / 100 \mathrm{~g}$, ) could be the result of hydrolysis of triacylglycerols during oil extraction (Manai et al., 2008; Rigane et al., 2013).

The second criterion for the quality of olive oil is the peroxide value (PV). This index is used to evaluate the oxidation state of oil during storage and must not exceed 20 meq $\mathrm{O}_{2} / \mathrm{kg}$ for all categories of olive oil (Commission Regulation. 1991).
The PV of the analysed olive oils (Tab. 1) is between 1.06 and 3.2 meq $\mathrm{O}_{2} / \mathrm{kg}$ being lower than the maximum values indicated by the regulations (Commission Regulation, 1991).

Measurements of absorbance at specific wavelengths ( $K_{232}$ and $\left.K_{270}\right)$ in the UV region are used to provide information on the oxidative state $\left(K_{232}\right)$ and a forbidden bleaching $\left(K_{270}\right)$ of olive oil (Hadorn and Zurcher, 1966). The absorbance $E_{232}$ showed low values for all oils ranging from 1.4 to 2.1 without exceeding the limit (2.5) defined by the European regulations (Commission Regulation, 1991). The absorption at $270 \mathrm{~nm}$ which provides information on the performance of a bleaching step showed for all virgin olive oil samples values below the limit of 0.22 given by the European regulations (Commission Regulation, 1991).

These results show that the type cultivar had no significant influence on these analytical quality parameters. These results are in agreement with data reported in the literature (Ben Temime et al., 2006).

\subsubsection{Fatty acid composition}

Table 1 shows the results of the main fatty acids of the four olive oil cultivars. Major fatty acid components present in all virgin olive oil samples were oleic acid (C18:1), linoleic acid (C18:2) and palmitic acid (C16:0). A low amount was found for palmitoleic acid (C16:1), stearic acid (C18:0), and linolenic acid (18:3). The fatty acid composition of the four oils was found to be in agreement with the European Regulations. On the other side significant differences were observed between the different cultivars.

Palmitic acid is the major saturated fatty acid in olive oil (Djebali et al., 2012) and its content was between 9.2\% (Moroccan Picholine) and $14.3 \%$ (Arebiquina) according to cultivars with an mean value of $12.6 \%$. For oleic acid, the main mono-unsaturated fatty acid of olive oil (Djebali et al., 2012), the highest values $(76.3 \%$ and $76.5 \%)$ were found in varieties Picual and Koroneiki, respectively while varieties Arebiquina (60.43\%) and Moroccan Picholine (64.33\%) showed significant lower amounts. Concerning linoleic acid, which is much more susceptible to oxidation than monounsaturated fatty acids (Manai et al., 2008), the highest percentage was observed in variety Arebiquina (13.2\%), whereas the lowest amount was found in variety Picual $(5.4 \%)$. The other samples showed percentages at $6.4 \%$ and $10.7 \%$ in varieties Koroneiki and Moroccan Picholine, respectively (Tab. 1). Linolenic acid belongs to the minor fatty acids of olive oil and according to the European Regulations (Commission Regulation, 1991) the concentration must be less than $1 \%$. The investigated oils were in agreement with European Regulations with values of linolenic acid between $0.7 \%$ and $0.9 \%$. Also the amount of the other minor fatty acids, palmitoleic acid and stearic acid varied in the different oils. For almost all oils the oleic acid to linoleic acid ratio was superior to the minimum value of 7 (Kiritsakis and Markakis, 1987), only variety Arebiquina should a ratio of 5.08 (Tab. 1). This ratio can be useful for the characterization of olive cultivars and for the interpretation of stability effects (Aparicio et al., 1999). Additionally the ratio between unsaturated and saturated fatty acids was found between 4.90 for olive oil from variety Arebequina oil and 7.00 for olive oil from Picholine. 
Table 1. Physicochemical parameters of extra virgin olive obtained from four varieties: Moroccan Picholine, Picual, Koroneiki and Arebiquina oils.

\begin{tabular}{|c|c|c|c|c|c|}
\hline & $\begin{array}{c}\text { European Regulations } \\
\text { (1991) for olive oil extra virgin }\end{array}$ & $\begin{array}{l}\text { Moroccan } \\
\text { Picholine }\end{array}$ & Picual & Koroneiki & Arebiquina \\
\hline Acidity (\%) & $<0.8$ & $0.6 \pm 0.02^{c}$ & $0.2 \pm 0.05^{\mathrm{a}}$ & $0.4 \pm 0.1^{\mathrm{b}}$ & $0.8 \pm 0.1^{\mathrm{d}}$ \\
\hline PV (Meq O2/kg) & $<20$ & $3.2 \pm 0.5^{\mathrm{c}}$ & $1.4 \pm 0.5^{\mathrm{ab}}$ & $1.06 \pm 0.50^{\mathrm{a}}$ & $2.1 \pm 0.5^{\mathrm{bc}}$ \\
\hline$E_{232}$ & $<2.5$ & $2.1 \pm 0.01^{\mathrm{c}}$ & $1.70 \pm 0.01^{\mathrm{b}}$ & $1.4 \pm 0.01^{\mathrm{a}}$ & $1.7 \pm 0.01^{\mathrm{b}}$ \\
\hline$E_{270}$ & $<0.22$ & $0.1 \pm 0.01^{\mathrm{a}}$ & $0.1 \pm 0.01^{\mathrm{a}}$ & $0.1 \pm 0.01^{\mathrm{a}}$ & $0.1 \pm 0.01^{\mathrm{a}}$ \\
\hline Palmitic acid C16:0 & $7.5-20$ & $9.2 \pm 0.1^{\mathrm{a}}$ & $12.7 \pm 1.5^{\mathrm{b}}$ & $12.5 \pm 1.5^{\mathrm{b}}$ & $14.3 \pm 0.1^{\mathrm{b}}$ \\
\hline Stearic acid C18:0 & $0.5-5$ & $2.9 \pm 0.1^{b}$ & $2.9 \pm 0.5^{\mathrm{b}}$ & $2.5 \pm 0.1^{\mathrm{a}}$ & $2 \pm 0.1^{\mathrm{a}}$ \\
\hline Oleic acid C18:1 & $55-83$ & $74.6 \pm 0.1^{\mathrm{b}}$ & $76.3 \pm 2.5^{\mathrm{b}}$ & $76.5 \pm 1.5^{\mathrm{b}}$ & $67.1 \pm 0.1^{\mathrm{a}}$ \\
\hline Linoleic acid C18:2 & $3.5-21$ & $10.7 \pm 0.1^{\mathrm{b}}$ & $5.4 \pm 1.5^{\mathrm{a}}$ & $6.4 \pm 0.1^{\mathrm{a}}$ & $13.2 \pm 0.1^{\mathrm{c}}$ \\
\hline Linolenic acid C18:3 & $<1$ & $0.9 \pm 0.1^{\mathrm{a}}$ & $0.7 \pm 0.1^{\mathrm{a}}$ & $0.7 \pm 0.1^{\mathrm{a}}$ & $0.8 \pm 0.1^{\mathrm{a}}$ \\
\hline $\mathrm{SFA}^{\mathrm{a}}(\mathrm{mg} / 100 \mathrm{mg})$ & & $12.4 \pm 0.1^{\mathrm{a}}$ & $15.6 \pm 0.1^{\mathrm{c}}$ & $15 \pm 0.1^{\mathrm{b}}$ & $16.6 \pm 0.1^{\mathrm{d}}$ \\
\hline $\operatorname{MUFA}^{\mathrm{a}}(\mathrm{mg} / 100 \mathrm{mg})$ & & $75.0 \pm 0.1^{\mathrm{b}}$ & $76.3 \pm 2.5^{b}$ & $76.5 \pm 1.5^{\mathrm{b}}$ & $67.1 \pm 0.1^{\mathrm{a}}$ \\
\hline PUFA $^{\mathrm{a}}(\mathrm{mg} / 100 \mathrm{mg})$ & & $11.8 \pm 0.1^{\mathrm{b}}$ & $6.1 \pm 0.1^{\mathrm{a}}$ & $7.1 \pm 0.1^{\mathrm{a}}$ & $14.3 \pm 0.1^{\mathrm{c}}$ \\
\hline $\mathrm{UFA}^{\mathrm{a}} / \mathrm{SFA}^{\mathrm{a}}$ & & $7.0^{\mathrm{a}}$ & $5.28^{\mathrm{a}}$ & $5.57^{\mathrm{a}}$ & $4.9^{\mathrm{a}}$ \\
\hline oleic acid/linoleic acid & & 6.97 & 14.13 & 11.95 & 5.08 \\
\hline Campesterol & $<4$ & $2.7 \pm 0.2^{\mathrm{a}}$ & $3.1 \pm 0.5^{\mathrm{ab}}$ & $3.2 \pm 0.2^{b}$ & $3.1 \pm 0.3^{\mathrm{ab}}$ \\
\hline Stigmasterol & $<$ Campesterol & $1.7 \pm 0.1^{\mathrm{a}}$ & $2.1 \pm 0.1^{\mathrm{a}}$ & $1.8 \pm 0.2^{\mathrm{a}}$ & $1.9 \pm 0.2^{\mathrm{a}}$ \\
\hline Beta-sterol (other sterols) & $>93$ & $93.8 \pm 0.5^{\mathrm{a}}$ & $94.2 \pm 7^{\mathrm{ab}}$ & $94.7 \pm 1.1^{\mathrm{ab}}$ & $94.8 \pm 0.5^{\mathrm{b}}$ \\
\hline 7 Stigmastenol & $<0.5$ & $0.2 \pm 0.1^{\mathrm{a}}$ & $0.4 \pm 0.1^{\mathrm{c}}$ & $0.3 \pm 0.1^{\mathrm{b}}$ & $0.3 \pm 0.1^{\mathrm{b}}$ \\
\hline 7 Avenasterol & - & $0.1 \pm 0.1^{\mathrm{a}}$ & $0.3 \pm 0.1^{\mathrm{a}}$ & $0.5 \pm 0.1^{\mathrm{a}}$ & \\
\hline Tocopherol (mg/kg) & - & $202 \pm 21^{\mathrm{a}}$ & $205 \pm 33^{\mathrm{a}}$ & $360.5 \pm 25^{\mathrm{b}}$ & $182 \pm 30^{\mathrm{a}}$ \\
\hline$\alpha$-Tocopherol (mg/kg) & - & $166.3 \pm 5^{\mathrm{a}}$ & $164 \pm 15^{\mathrm{a}}$ & $324 \pm 25^{\mathrm{b}}$ & $167 \pm 5^{\mathrm{a}}$ \\
\hline Polyphenol (mg/kg) & - & $275 \pm 20^{\mathrm{b}}$ & $295 \pm 25^{\mathrm{b}}$ & $320 \pm 30^{c}$ & $136 \pm 25^{\mathrm{a}}$ \\
\hline
\end{tabular}

* Values are means of three replicates \pm standard deviation. Values in the same row with different superscripts are significantly different $(p \leqslant 0.05)$. UFA: Unsaturated fatty acid; SFA: Saturated fatty acid, MUFA: Monounsaturated fatty acid, PUFA: Polyunsaturated fatty acid.

\subsubsection{Sterol composition}

Sterols are important minor constituents in vegetable oils and they are widely used to verify the authenticity (Al-Ismail et al., 2010; Rigane et al., 2013). Besides, their determination is of major interest due to their health benefits, as discussed before (Koutsaftakis et al., 1999). Table 1 shows the sterol composition obtained for the different olive oils. The sterol composition shown in this study is in contrast to the literature (Aparicio et al., 2002), which stated that the cultivar of the olive tree influences the proportion of sterols. In the present work no significant differences in the composition of sterols between the different cultivars was found. According to our results, the olive oils studied are characterized by a high content of $\beta$-sitosterol, comprising more than $93 \%$ of the total sterols in the four varieties (Tab. 1). This is in agreement with other results already reported in the literature (Al-Ismail et al., 2010; Allalout et al., 2009; Aparicio et al., 2002; Djebali et al., 2012; Gharby et al., 2012; Rigane et al., 2013).

\subsubsection{Tocopherols composition}

Tocopherols are important molecules due to their role as vitamins in nutrition or their ability to intercept free radicals (Aparicio et al., 2002, Canâbate-Diaz et al., 2007). $\alpha$-tocopherol is the major vitamin-E-active compound in the olive oil (Gharby et al., 2012). As shown in Table 1, significant differences between the cultivars were found for the total tocopherols content and the content of $\alpha$-tocopherol. The highest amount of total tocopherols was observed in the variety Koroneiki $(360 \mathrm{mg} / \mathrm{kg}$ ); whereas, the lowest amount was recorded in variety Arebiquina cultivar $(182 \mathrm{mg} / \mathrm{kg})$, with amounts for varieties Moroccan Picholine and Picual of $166.3 \mathrm{mg} / \mathrm{kg}$ and $164 \mathrm{mg} / \mathrm{kg}$ respectively The amount $\alpha$-tocopherol in virgin olive oil depends on several factors such as variety, fruit ripeness, and agro-climatic conditions. Among these factors, variety is the most important reason for variation (Krichene et al., 2007).

\subsubsection{Total phenol content}

Phenolic compounds contribute to the nutritional importance and benefit to human health of virgin olive oil and they are responsible for bitter taste and the antioxidant activity of the oil (Garc et al., 2003; Kharazi et al., 2012). Therefore the content of phenolic compounds is an important parameter which determines the characteristics and quality of olive oil (Garcia et al., 2002; Kowalski et al., 2004). The total amounts of phenolic compounds in olive oil depend on various factors such as cultivar, climate and irrigation, altitude and technological conditions during extraction (Garc et al. 2003; Garcia et al., 2002). The amounts of total phenols in the analyzed oils show significant differences between different varieties (Tab. 1). The highest content of these components was detected in oil from variety Koroneiki $(320.5 \mathrm{mg} / \mathrm{kg})$, whereas the lowest amount was recorded for oil from variety Arbequina (136 mg/kg). 
Table 2. Rancimat measurements of extra virgin olive oils obtained from four varieties.

\begin{tabular}{ccccccc}
\hline & $373 \mathrm{~K}$ & $383 \mathrm{~K}$ & $393 \mathrm{~K}$ & $403 \mathrm{~K}$ & $413 \mathrm{~K}$ & $423 \mathrm{~K}$ \\
\hline Arebiquina & $25.1 \pm 1$ & $11.9 \pm 1.5$ & $5.9 \pm 1$ & $3.1 \pm 1$ & $1.4 \pm 0.5$ & $0.6 \pm 0.5$ \\
Moroccan Picholine & $44.1 \pm 2$ & $18.4 \pm 1.5$ & $9.2 \pm 1.5$ & $4.4 \pm 1$ & $1.8 \pm 0.5$ & $0.9 \pm 0.5$ \\
Koroneiki & $59 \pm 2.5$ & $31.5 \pm 2.5$ & $16.6 \pm 1.5$ & $9.1 \pm 1.5$ & $4.4 \pm 0.5$ & $1.8 \pm 1.5$ \\
Picual & $49.6 \pm 1.5$ & $26.1 \pm 1$ & $12 \pm 1.5$ & $5.7 \pm 1$ & $2.3 \pm 0.5$ & $1.2 \pm 0.5$ \\
\hline
\end{tabular}

Table 3. The reaction rate constants $(k)$ of the olive oils at different temperatures.

\begin{tabular}{ccccccc}
\hline \multicolumn{7}{c}{$k \pm S \mathrm{D}\left(6 \times 10^{3}\right)\left(\mathrm{h}^{-1}\right)$} \\
\hline & $373 \mathrm{~K}$ & $383 \mathrm{~K}$ & $393 \mathrm{~K}$ & $403 \mathrm{~K}$ & $413 \mathrm{~K}$ & $423 \mathrm{~K}$ \\
\hline Arebiquina & $39.8 \pm 0.3$ & $84.03 \pm 0.6$ & $169.5 \pm 1.4$ & $322.5 \pm 3.2$ & $714.3 \pm 3.8$ & $1666.6 \pm 5.1$ \\
Moroccan Picholine & $22.6 \pm 0.2$ & $54.3 \pm 0.5$ & $108.7 \pm 1.5$ & $227.3 \pm 3.1$ & $555.5 \pm 4.5$ & $1111.1 \pm 5.6$ \\
Koroneiki & $16.94 \pm 0.2$ & $31.7 \pm 0.5$ & $60.2 \pm 0.8$ & $109.9 \pm 2.5$ & $227.3 \pm 3.5$ & $555.5 \pm 4.5$ \\
Picual & $20.2 \pm 0.2$ & $38.3 \pm 0.6$ & $83.3 \pm 1.2$ & $175.4 \pm 2.5$ & $434.8 \pm 3.6$ & $833.3 \pm 5$ \\
\hline
\end{tabular}

\subsection{Kinetic analysis of the Rancimat data}

The oils studied displayed relatively high stabilities at $373 \mathrm{~K}$ (Tab. 2) in the range between $25.1 \mathrm{~h}$ (Arebiquina) and $59.0 \mathrm{~h}$ (Koroneiki) with longer induction times for the more stable oils. Heating of the oils under Rancimat conditions shows that the induction times as measures for the thermaloxidative decomposition of the oils strongly depend on the temperature. The induction times for the oils from the four varieties can be ranked as Koroneiki $>$ Picual $>$ Moroccan Picholine $>$ Arebquina in the temperature range from $373 \mathrm{~K}$ to $413 \mathrm{~K}$ while at $423 \mathrm{~K}$ no significant difference between the different oils was found. There are several reports that the ranking of oil and fat resistance to thermal-oxidative decomposition strongly depends on temperature (Kowalski et al., 2004; Litwinienko, 2005).

The $k$ values for lipid oxidation of each olive oil at each temperature are presented in Table 3. By studying the rates of lipid oxidation as a function of temperature, an increasing rate of oxidation can be observed as temperature increases. As revealed in Figure 1, the semi-logarithmic relationship between $k$ and $\mathrm{T}$ values in all virgin olive oils showed a linear dependency with good correlation of determination $\left(R^{2}>0.99\right)$ and they can be described by the following equation:

$$
\ln (k)=a(T)+b
$$

where $a$ and $b$ are adjustable coefficients and $T$ is the temperature in $\mathrm{K}$.

The lipid oxidation at low and high temperatures may go through different steps or reaction pathways, depending on the reactivity of prooxidants such as metal ions and antioxidants at different temperatures (Tan et al., 2001). Furthermore, the oil temperature affects the degree of oxygen solubility in vegetable oils which decreases by almost $25 \%$ for each $10 \mathrm{~K}$ rise in temperature (Robertson, 2000). The values for the temperature coefficient calculated from the linear functions in Figure 1 for the olive oils ranged from $6.8 \times 10^{-2}$ to $7.7 \times 10^{-2} \mathrm{~K}^{-1}$. The lowest value was calculated for variety Koroneiki, while the highest value of $T_{\text {Coeff }}\left(7.3 \times 10^{-2} \mathrm{~K}^{-1}\right)$ was found for variety Arbequina. For varieties Picholine and Picual Figure 1 shows the same values $\left(7.7 \times 10^{-2} \mathrm{~K}^{-1}\right)$. Similar results were described by Farhoosh et al. (2008) for deodorized olive oil $\left(6.65 \times 10^{-2} \mathrm{~K}^{-1}\right)$ and for other oils (canola oil,

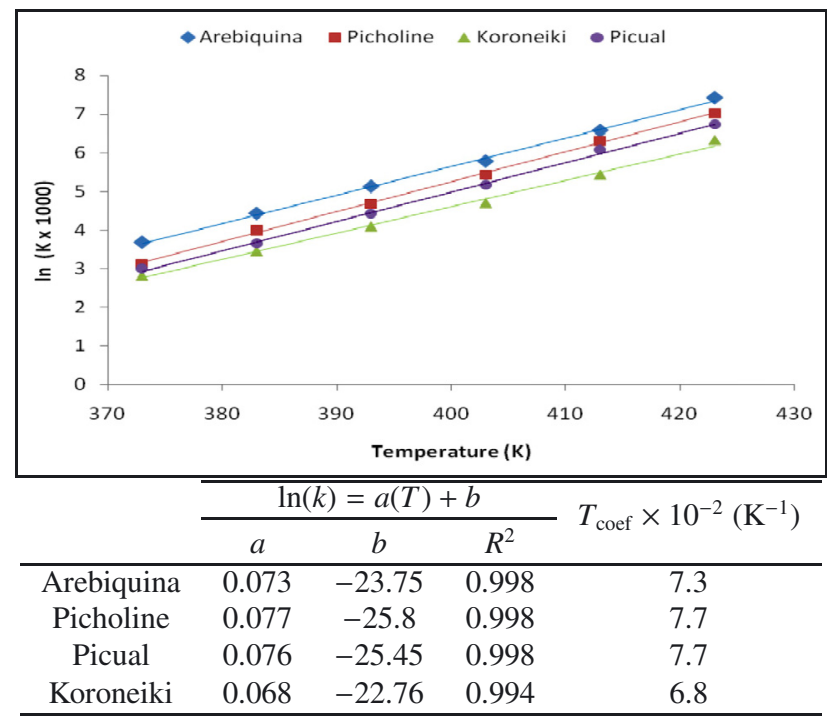

Fig. 1. Semi-logarithmic relationship between $k$ and $T$ values for lipid oxidation of the four olive oils.

soybean oil, sunflower oil and corn oil) they found values between $6.5 \times 10^{-2}$ and $7.4 \times 10^{-2} \mathrm{~K}^{-1}$. In a recent study on argan oil, Zaanoun et al. (2014) found comparable values for roasted $\left(7.2 \times 10^{-2} \mathrm{~K}^{-1}\right)$ and for unroasted argan oil $\left(7.5 \times 10^{-2} \mathrm{~K}^{-1}\right)$.

Table 3 provides the regression parameters for the Arrhenius relationships between the reaction rate constant and the temperature for the four virgin olive oils studied $(\ln (k)=$ $\left.\ln (A)-\left(E_{a} / R\right) \times(1 / T)\right)$. Using these regression parameters, frequency factors $\left(A, \mathrm{~h}^{-1}\right)$, activation energies $\left(E_{a}, \mathrm{~kJ} / \mathrm{mol}\right)$, and $Q_{10}$ numbers for the formation reaction of the secondary oxidation products under the Rancimat test conditions (volatile acids, mostly formic acids, with lower amounts of acetic acid, propionic acid, and other acids) were calculated (DeMan et al., 1987). These values for the lipid oxidation of the olive oils under the Rancimat test conditions differed significantly. This implies that the formation of volatile acids under these conditions was dependent on the oil source which affects assessment of the relative stability of the olive oils (Mendez et al., 1996).

The results obtained showed that a lower degree of polyunsaturation and the high content of polyphenols and tocopherols would improve the resistance to the lipid oxidation 
Table 4. Regression parameters for Arrhenius relationships between the reaction rate constant and the temperature for the four olive oils.

\begin{tabular}{ccccccc}
\hline & \multicolumn{7}{c}{$\left.\ln (k)=\ln (A)-E_{a} / R\right) \times(1 / T)$} \\
\cline { 2 - 7 } & $a$ & $b$ & $R^{2}$ & $E_{a}$ & $A$ & $Q_{10}$ \\
\hline Arebiquina & -11.58 & 34.65 & 0.994 & -96.279594 & $1.11764 E+15$ & 2.1 \\
Picholine & -12.24 & 35.91 & 0.997 & -101.767032 & $3.94017 E+15$ & 2.2 \\
Koroneiki & -10.76 & 31.57 & 0.988 & -89.461868 & $5.13661 E+13$ & 2.0 \\
Picual & -11.99 & 35.02 & 0.995 & -99.688457 & $1.61805 E+15$ & 2.1 \\
\hline
\end{tabular}

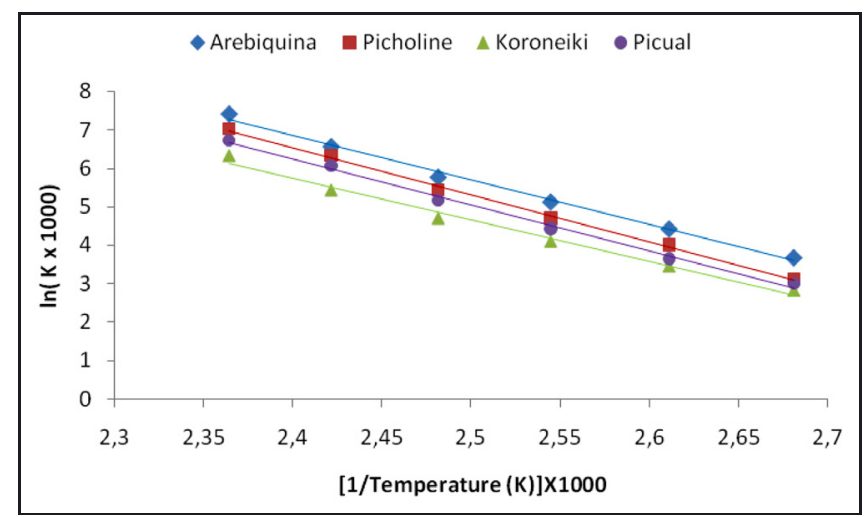

Fig. 2. Semi-logarithmic relationship between $k$ and $1 / T$ values for lipid oxidation of the four olive oils.

(raise the $E_{a}$ value). Adhvaryu et al. (2000) showed that a high PUFA (linoleic acid and linolenic acid content) would lower the activation energies $\left(E_{a}\right)$ value for lipid oxidation but a high oleic acid content would increase it. These would result in delaying the beginning of the initial oxidation process where bond scission takes place to form primary oxidation products. The polyphenol and tocopherols contents of the olive oils (Tab. 1) explain the observed trends in various activation energies (Tab. 4) to a certain extent. The olive oil from variety Koroneiki with the lowest content of polyunsaturated fatty acids, the highest ratio of oleic acid to linoleic acid and the highest content of antioxidants (tocopherols and polyphenols) showed the highest activation energy. However, it was observed that several other factors affecting the oxidative stability. Olive oil from variety Arebiquina had the lowest content of tocopherols and polyphenols and also the highest value of linoleic aicd, but the activation energy was the second-highest value. One reason could be the higher content of palmitic acid in comparison to the other oils. The frequency factors with a trend comparable to that of the activation energy values for the olive oils studied increased from $1.11 \times 10^{15}$ for Arebiquina to $5.13 \times 10^{13}$ for Koroneiki.

The magnitude of the temperature effect on the oxidation rate of the olive oils is evidenced by the $Q_{10}$ numbers. In general, a higher $Q_{10}$ number implies that a smaller temperature change is needed to induce a certain change in the rate of lipid oxidation. As can be seen in Table 4, the $Q_{10}$ number increased from 2.0 for Koroneiki to 2.2 for Picholine, thus for olive oil from variety Koroneiki a higher temperature than for the other varieties is necessary to result in changes in the rate of lipid oxidation.

The $\Delta H$ and $\Delta S$ values estimated based on the activated complex theory (Labuza, 1980) and the corresponding

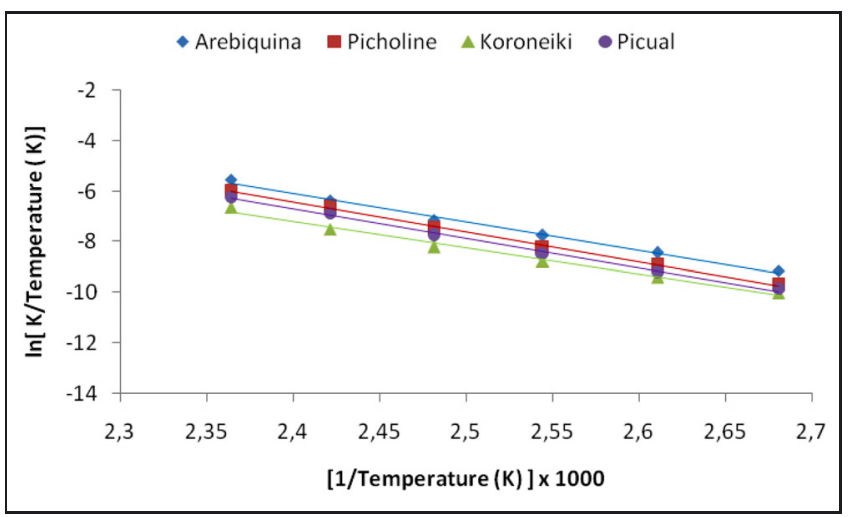

Fig. 3. Semi-logarithmic relationship between $(k / T)$ and $(1 / T)$ values for lipid oxidation of the four olive oils.

regression parameters are summarized in Table 5. The high correlation of determination $\left(R^{2}>0.98\right)$ indicated adequate fit and characterization of the temperature dependence of lipid oxidation when using the activated complex theory.

The $\Delta H$ values for the olive oils studied ranged from $86.21 \mathrm{~kJ} / \mathrm{mol}$ for oil from variety Koroneiki to $98.44 \mathrm{~kJ} / \mathrm{mol}$ for oil from variety Picholine. The $\Delta S$ values ranged from $-50.55 \mathrm{~J} / \mathrm{mol} \mathrm{K}$ for oil from variety Koroneiki to $-14.54 \mathrm{~J} / \mathrm{mol} \mathrm{K}$ for oil from variety Picholine. In their study on the determination of the oxidative stability of rapeseed, sunflower and soybean oils by the Rancimat test, Kowalski et al. (2004) calculated the $\Delta H$ - and $\Delta S$-values as $82 \mathrm{~kJ} / \mathrm{mol}$ and $-52.7 \mathrm{~J} / \mathrm{mol} \mathrm{K}, 84 \mathrm{~kJ} / \mathrm{mol}$ and $-42.8 \mathrm{~J} / \mathrm{mol} \mathrm{K}$, and $74.9 \mathrm{~kJ} / \mathrm{mol}$ and $-70.2 \mathrm{~J} / \mathrm{mol} \mathrm{K}$, respectively. The negative values for $\Delta S$ indicate that the activated complexes are more ordered than the molecules of the reactants, as can be seen in Table 5. The greater negative $\Delta S$ value for oil from variety Koroneiki indicates fewer numbers of species in the activated complex state. Hence, the activated complex for lipid oxidation in oil from variety Koroneiki is less probable and therefore the rate is slower. So it can be stated that the oil from variety Koroneiki is the more stable oil.

Tan et al. (2001) evaluated the oxidative stability of vegetable oils by Differential Scanning Calorimetry and showed that the $\Delta H$ and $\Delta S$ values were greater for highly unsaturated oils than for oils with lower amounts of unsaturated fatty acids, which corroborate with our study. Olive oil from variety Koroneiki with the lowest ratio of unsaturated to saturated fatty acids showed the lowest values for $\Delta H$ and $\Delta S$. Also for olive oil from varieties Arebiquina and Picual $\Delta H$ and $\Delta S$ values showed a good agreement with the ratio saturated to unsaturated fatty acids while for oil from variety Picholine the values were low although the ratio was high (Tab. 1). 
Table 5. Activation enthalpies $\Delta H$ and entropies $\Delta S$ for lipid oxidation of the four olive oils.

\begin{tabular}{cccccc}
\hline & \multicolumn{6}{c}{$\ln (k / T)=\ln (k B / h)+(\Delta S / R)-\Delta H / R) \times(1 / T)$} \\
\cline { 2 - 6 } & $a$ & $b$ & $R^{2}$ & $\Delta H(\mathrm{~kJ} / \mathrm{mol})$ & $\Delta S(\mathrm{~J} / \mathrm{mol} \mathrm{K})$ \\
\hline Arebiquina & -11.18 & 20.76 & 0.994 & 92.953874 & -24.942763 \\
Picholine & -11.84 & 22.01 & 0.997 & 98.441312 & -14.549888 \\
Picual & -11.59 & 21.13 & 0.994 & 96.362737 & -21.866472 \\
Koroneiki & -10.37 & 17.68 & 0.988 & 86.219291 & -50.550807 \\
\hline
\end{tabular}

\section{Conclusion}

The investigation showed that olive oils from different varieties where different regarding their chemical parameters such as acidity, peroxide value, fatty acid, tocopherol and phytosterol content and composition and physical parameters such as $E_{232}$ and $E_{270}$. The measurement of the thermal stability as induction time by Rancimat at different temperatures revealed a strong dependency from the temperature, but also a strong influence of the variety was given. The Rancimat method was an accurate and effective method to investigate the kinetic data of lipid oxidation in olive oils at elevated temperature. The lowest value for the temperature coefficient was calculated for variety Koroneiki, while the highest value was found for variety Arbequina which may be influenced by the low content of linoleic acid prone to oxidation and the high content of antioxidant active compounds of oil from variety Koroneiki in comparison to olive oil from variety Arbequina. The oil from variety Koroneiki was the most stable oil in this investigation in comparison to oils from other varieties. The results of the kinetic calculations were also in good agreement with the fatty acid composition and the content of antioxidant active compounds. Thus, the calculation of different kinetic parameters such as activation energy or enthalpies $(\Delta H)$ and entropies $(\triangle S)$ could be important factors to access the thermal stability of olive oils.

\section{References}

Adhvaryu A, Erhan SZ, Liu ZS, Perez JM. 2000. Oxidation kinetic studies of oils derived from unmodified and genetically modified vegetables using pressurized differential scanning calorimetry and nuclear magnetic resonance spectroscopy. Thermochim. Acta 364: 87-97.

Al-Ismail KM, Alsaed AK, Ahmad R, Al-Dabbas M. 2010. Detection of olive oil adulteration with some plant oils by GLC analysis of sterols using polar column. Food Chem. 121: 1255-1259.

Allalout A, Krichéne D, Methenni K, et al. 2009, Characterization of virgin olive oil from Super Intensive Spanish and Greek varieties grown in northern Tunisia, Sci. Hortic. 120: 77-83.

Anwar F, Bhanger MI, Kazi TG. 2003. Relationship between Rancimat and Active Oxygen Method values at varying temperatures for several oils and fats. J. Am. Oil. Chem. Soc. 80: $151-155$.

Aparicio R, Luna G. 2002. Characterisation of monovarietal virgin olive oils. Eur. J. Lipid. Sci. Technol. 104: 614-627.

Aparicio R, Roda L, Albi MA, Gutierrez F. 1999. Effet of various compounds on virgin olive oil stability measured by Rancimat. $J$. Agric. Food. Chem. 47: 4150-4155.
Ben Temime S, Campeol E, Cioni PL, Daoud D, Zarrouk M. 2006 Volatile compounds from Chetoui olive oil and variations induced by growing area. Food Chem. 99: 315-325.

Canâbate-Diaz B, Segura-Carretero A, Fernandez-Gutierrez A, et al. 2007. Separation and determination of sterols in olive oil by HPLC-MS. Food Chem. 102: 593-8.

Commission Regulation (EEC). 1991. No. 2568/91, on the characteristics of olive oil and olive-residue oil and on the relevant methods of analysis, Official Journal L 248, 5 September 1991, pp. 1-83.

Dabbou S, Rjiba I, Nakbi A, Gazzah N, Issaoui M, Hammami M. 2010, Compositional quality of virgin olive oils from cultivars introduced in Tunisian arid zones in comparison to Chemlali cultivars, Scientia Horticulturae 124: 122-127.

DeMan JM, Tie F, DeMan L. 1987. Formation of short chain volatile organic acids in the automated AOM method. J. Am. Oil Chem. Soc., 64: 993-996

Djebali HM, Krichene D, Ouni Y, et al. 2012. Chemical profiles of five minor olive oil varieties grown in central Tunisia. J. Food Compos. Anal. 27: 109-119.

Farhoosh R, Niazmand R, Rezaei M, Sarabi M. 2008. Kinetic parameter determination of vegetable oil oxidation under Rancimat test conditions. Eur. J. Lipid Sci. Technol. 110: 587-592.

Frankel EN. 2007. Antioxidants in food and biology. Dundee: The Oily Press LD.

Garc A, Brenes M, Garc P, Romero C, Garrido A. 2003. Phenolic content of commercial olive oils. Eur. Food. Res. Technol. 216: $520-525$.

Garcia A, Brenes M, Romero C, Garcia P, Garrido A. 2002. Study of phenolic compounds in virgin olive oils of the Picual variety. Eur. Food Res. Technol. 215: 407-412

Gharby S, Harhar H, El Monfalouti H., et al. 2011. Chemical and oxidative properties of olive and argan oils sold on the Moroccan market. A comparative study. Med. J. Nutrition Metab. 44: 1-8.

Gharby S, Harhar H, Guillaume D, Haddad A, Charrouf Z. 2012. The origin of virgin argan Oil's high oxidative stability unraveled. Nat. Prod. Commun. 7: 621-624.

Gharby S, Harhar H, Kartah B, Chafchauni I, Sibawayh Z., Charrouf Z. 2013. Chemical Characterization and oxidative stability of two monovarietal virgin olive oils (Moroccan Picholine and Arbequina) grown in Morocco. J. Mater. Environ. Sci. 4: 935-942.

Gutierrez F, Varona I, Albi MA. 2000. Relation of acidity and sensory quality with sterol content of olive oil from stored fruit. J. Agric. Food Chem. 48: 1106-1110.

Hasenhuettl GL, Wan PJ. 1992. Temperature effects on the determination of oxidative stability with the Metrohm Rancimat. J. Am. Oil. Chem. Soc. 69: 525-527.

Hadorn, H, and Zürcher, K. 1966. Beurteilung von Speiseölen auf Grund des UV-Differenz-Spektrums. Mitt. Geb. Lebensmittelunters. Hyg. 57: 189-231.

ISO 5508. 1990. Animal and vegetable fats and oils - Analysis by gas chromatography of methyl esters of fatty acids. 
ISO 6799. 1991. Determination of the sterol fraction by gas chromatography.

ISO 6886. 2006. Animal and vegetable fats and oils - Determination of oxidative stability (accelerated oxidation test).

ISO 9936. 2006. Animal fats and vegetable - Determination of tocopherols and tocotrienols by liquid chromatography high performance.

Kharazi SH, Kenari RE, Amiri ZR, Azizkhani M. 2012. Characterization of Iranian olive oil from the roodbar region: A study on Zard, Mari and Phishomi. J. Am. Oil. Chem. Soc. 89: 1241-1247.

Kiritsakis A, Markakis P. 1987. Olive oil: a review. Adv. Food Res. 31: 453-482.

Koutsaftakis A, Kotsifaki F, Stefanoudaki E. 1999. Effect of extraction system, stage of ripeness, and kneading temperature on the sterol composition of virgin olive oils. J. Am. Oil. Chem. Soc. 76: 1477-1481.

Kowalski B. 1989. Determination of oxidative stability of edible vegetable oils by pressure differential scanning calorimetry. Thermochim Acta. 156: 347-358.

Kowalski B, Ratusz K, Kowalska D, Bekas W. 2004. Determination of the oxidative stability of vegetable oils by differential scanning calorimetry and Rancimat measurements. Eur. J. Lipid Sci. Technol. 106: 165-169.

Krichene D, Taamalli W, Daoud D, Salvador MD, Fregapane G, Zarrouk M. 2007. Phenolic compounds, tocopherols and other minor components in virgin olive oils of some Tunisian varieties. J. Food Biochem. 31: 179-194.

Labuza TP. 1980. Enthalpy/Entropy Compensation in Food Reactions, Food Technol. 34: 67-77.

Litwinienko G. 2005. Analysis of lipid oxidation by differential scanning calorimetry. In: Kamal-Edin A, Pokorny J, eds. Analysis of Lipid Oxidation. Champaign, IL (USA): AOCS Press, pp. 152-193.

Manai H, Mahjoub-Haddada F, Oueslati I, Daoud D, Zarrouk M. 2008, Characterization of monovarietal virgin olive oils from six crossing varieties. Scientia Horticulturae 115: 252-260.

Mancebo-Campos V, Salvador MD, Fregapane G. 2007. Comparative study of virgin olive oil behavior under Rancimat accelerated oxidation conditions and long-term room temperature storage. $J$. Agric. Food Chem. 55: 8231-8236.

Marques-Ruiz G, Martin-Polvillo M, Velasco J, Dobarganes C. 2008. Formation of oxidation compounds in sunflower and olive oils under oxidative stability index conditions. Eur. J. Lipid Sci. Technol. 110: 465-471.
Mataix J, Battino M, Ramirez-Tortosa MC, Bertoli E, Quiles J. 2008. Virgin olive oil: a key healthy component of the Mediterranean diet. Med. J. Nutrition Metab. 1: 69-75

Matthäus B. 1996. Determination of the oxidative stability of vegetable oils by Rancimat conductivity and chemiluminescence measurements. J. Am. Oil. Chem. Soc. 73: 1039-1043.

Matthäus B, Guillaume D, Gharby S, Haddad A, Harhar H, Charrouf Z. 2010. Effect of processing on the quality of edible argan oil. Food Chem. 120: 426-432.

Mendez E, Sanhueza J, Speisky H, Valenzuela A. 1996. Validation of the Rancimat test for the assessment of the relative stability of fish oils. J. Am. Oil. Chem. Soc. 73, 1033-1037.

Morello JR, Motilva MJ, Tovar MJ, Romero MP. 2004. Changes in commercial virgin olive oil during storage, with special emphasis on the phenolic fraction. Food Chem. 85: 357-364.

Owen RW, Mier W, Giacosa A, Hull WE, Spiegelhalder B, Bartsch H. 2000. Identification of lignans as major components in the phenolic fraction of olive oil. Clin. Chem. 46: 976-988.

Ratusz K, Kowalski B, Gruczynska E, Tarnowska K, Bekas W, Kowalska M. 2002. Evaluation of antioxidants activity in vegetable oils and triacylglycerol matrices by Rancimat measurements. Riv. Ital. Sost. Grasse. 79: 251-255.

Reynhout G. 1991. The effect of temperature on the induction time of a stabilized oil. J. Am. Oil Chem. Soc. 68: 983-984.

Rigane G, Ayadi M, Boukhris M, Sayadi S., Bouaziz M. 2013. Characterisation and phenolic profiles of two rare olive oils from southern Tunisia: Dhokar and Gemri-Dhokar cultivars. J. Sci. Food Agric. 93: 527-534.

Robertson GL. 2000. Shelf life of packaged foods, its measurements and prediction. In: AL Brody, JB Lord, eds., Developing New Food Products for a Changing Marketplace. Lancaster (UK): Tech-nomic Publishing, pp. 329-353.

Singleton VL, Orthofer R, Lamuela-Raventos RM. 1999, Analysis of total phenols and other oxidation substrates and antioxidants by means of Folin-Ciocalteau reagent. Methods Enzymol. 299: $152-178$.

Tan CP, Che Man YB, Selamat J, Yusoff MA. 2001. Application of Arrhenious kinetics to evaluate oxidative stability in vegetable oils by isothermal differential scanning calorimetry. J. Am. Oil. Chem. Soc. 78: 1133-1138.

Velasco J, Dobarganes C. 2002. Oxidative Stability of Virgin olive Oil. Eur. J. Lipid Sci. Technol. 104: 661-676.

Zaanoun I, Gharby S, Bakass I, Ait addi E, Ait Ichou I. 2014. Kinetic parameter determination of roasted and unroasted argan oil oxidation under Rancimat test conditions. Grasas y Aceites 65: e033.

Cite this article as: Said Gharby, Hicham Harhar, Rachid Mamouni, Bertrand Matthäus, El Habib Ait Addi, Zoubida Charrouf. Chemical Characterization and Kinetic parameter determination under Rancimat test conditions of four monovarietal virgin olive oils grown in Morocco. OCL 2016, 23(4) A401. 